BACKGROUND: Infection in the neonatal period is an extremely serious condition and diagnosis is difficult. C-reactive protein (CRP) is widely used as a marker of infection; however, its usefulness is limited in the early phase. The role of soluble intracellular adhesion molecule-1 (sICAM-1), an adhesion molecule, has been examined in recent studies as an early marker of neonatal infection with controversial results.

Aim: Assessment of sICAM-1 concentrations and correlation with CRP, which is the currently used marker of infection, in order to use SICAM as an early diagnostic tool in neonates suspected for infection Methods: Blood samples and blood cultures were obtained from two groups of pre-term and full-term neonates with clinical suspicion of infection prior to the initiation of antibiotics. The SICAM-1 and CRP values were compared with the corresponding noninfected ones $(n=10$ each).

Results: The sICAM-1 levels were found increased in the group of both premature and term neonates with infection compared with the corresponding healthy ones $(p<0.0001)$. Prematurity combined with infection resulted in excessive increase of the levels of SICAM-1 in comparison with full-term infected newborns $(p<0.001)$. CRP values were normal in all samples except one in both full-term and premature infected neonates on day 1 of clinically suspected infection. Serial detection of CRP values on days 2 and 4 of infection revealed a pattern according to which CRP values in premature neonates continued rising, while in the group of full terms these values, after rising on the second day, lowered on day 4 .

Conclusions: Increased sICAM-1 levels can be detected early in both full-term and premature neonates with sepsis while CRP levels are within normal range at the same time. Assessment of sICAM-1 concentrations may be used as a diagnostic tool in neonates suspected for infection, resulting in earlier initiation of antibiotic therapy and therefore improving their outcome.

Key words: Adhesion molecules, C-reactive protein, sICAM-1, Infection, Prematurity, Full-term neonates

\section{Levels of soluble ICAM-1 in premature and full-term neonates with infection}

\author{
Melita Apostolou' ${ }^{1}$, Helen Dimitriou ${ }^{2}$, \\ Joseph Kaleyias ${ }^{1}$, Chrissoula Perdikogianni ${ }^{2}$, \\ Eftichia Stiakaki ${ }^{2}$, Christos Costalos ${ }^{1}$ and \\ Maria Kalmanti ${ }^{2, C A}$,
}

\begin{abstract}
${ }^{1}$ Neonatology Department, State Maternity Hospital 'Alexandra', Athens, Greece; and 'Department of Pediatric Haematology-Oncology, University Hospital of Heraklion, University of Crete, Medical School, PO Box 1393, Heraklion, Crete, Greece
\end{abstract}

\footnotetext{
${ }^{\mathrm{CA}}$ Corresponding Author

Tel: +30 81392630

Fax: +30 81392778

E-mail: pedhem@med.uoc.gr
}

\section{Introduction}

The immune system is not completely developed at birth. Infection in the neonatal period is an extremely serious condition and diagnosis is difficult due to the lack of specific clinical symptoms and reliable early laboratory indicators. Especially, premature neonates have a reduced capacity to resist the infection, and this impaired host defense results in increased morbidity and mortality in the neonatal period, particularly among pre-term infants. Isolation of the causative organism from blood cultures takes up to $72 \mathrm{~h}$ and does not identify most infected infants. C-reactive protein (CRP) is widely used as a marker of infection and has been proved to be very effective for early detection of sepsis. ${ }^{1,2}$ However, the delayed rise after the onset of the infection (up to $12 \mathrm{~h}$ ) limits its usefulness in the early phase. ${ }^{3}$ Intercellular adhesion molecule-1 (ICAM-1) participates in the adhesion of leukocytes to the endothelium and may be crucial in regulating leukocyte activation at a very early inflammatory response. ${ }^{4}$ Expression of adhesion molecules is regulated by cytokine activation, and it has been shown that several membrane-bound adhesion molecules can be detected in the circulation in a soluble form. ${ }^{5}$ Soluble ICAM-1 (sICAM-1) is normally present in the serum of healthy adults, ${ }^{6}$ and recent studies examined the role of sICAM- 1 in neonatal infections, but with controversial results. ${ }^{7-10}$ The aim of this study is to compare ICAM-1 and CRP values in 
infected and non-infected newborns, to evaluate the effect of prematurity on SICAM-1 expression, and to correlate with the presence of infection and CRP values in an effort to establish an early marker for detection of infection in newborns.

\section{Material and methods}

All newborn infants that were participating in the study had been delivered at the State Maternal Hospital Alexandra, Athens during a 3-month period (January 2000-March 2000).

The infants were recruited into the study at the time of evaluation for suspected clinical infection. Inclusion criteria were the clinical suspicion of infection based on general symptoms (pallor or icterus), neurological symptoms (lethargy, apnea, bradycardia, irritability, seizures), respiratory symptoms (tachypnea, retractions or respiratory distress), cardiovascular symptoms (compromised microcirculation, tachycardia or hypotension), abdominal symptoms (abdominal distension or vomitus) and fever or temperature instability.

Antibiotic treatment was started when indicated (according to established clinical routine). Blood samples for sICAM-1 determination and blood cultures were obtained when the first clinical suspicion for infection was raised and prior to the initiation of antibiotics. The blood sample for sICAM-1 determination from the premature controls was matched to the day of life of a newly diagnosed infected one, while that from the full-term controls was taken the third day of life on their release from the hospital. The serum was separated by centrifugation and was stored at $-20^{\circ} \mathrm{C}$ until assay. During the study period, 21 neonates fulfilled the inclusion criteria. For each newborn with clinical suspicion of infection, a non- infected infant control has been included in the study according to the gestational age. The infants were classified into two groups. Group 1 (control) included 10 healthy full-term and 10 premature neonates (gestational age, 25-35 weeks) without signs of infection. Group 2 included 21 neonates (10 term neonates, 11 pre-term neonates) with generalized infection on the basis of the reported clinical criteria. Ten out of 21 neonates of group 2 had positive blood cultures.

For quantitation of sICAM-1 in serum samples, the commercial enzyme-linked immunosorbent assay, ELISA-kit, was used (R\&D Systems, Minneapolis, MN, USA) following the manufacturer's instructions. The assay is based on a sandwich ELISA principle with horseradish peroxidase-labeled secondary antibodies. The characteristics of the study groups are presented in Table 1. Written informed consent was obtained from all parents (mother and/or father), and the study has been approved by the Ethics Committee of the Hospital.

\section{Statistical analysis}

All measurements were performed in duplicate. The results of each group are expressed as the mean value $(\mathrm{ng} / \mathrm{ml}) \pm$ standard error of the mean. Differences between groups were assessed by two-tail unpaired $t$-test. Correlations were determined by Pearson's coefficient $(r) . p<0.05$ was considered to indicate statistical significance

\section{Results}

The sICAM-1 levels were found increased in the group of term neonates with infection $(710.7 \pm 56.6 \mathrm{ng} / \mathrm{ml})$ compared with the healthy full-term neonates $(358.4$

Table 1. Clinical and laboratory characteristics of the study groups

\begin{tabular}{|c|c|c|c|c|c|}
\hline & $\begin{array}{l}\text { Full term } \\
\text { neonates }\end{array}$ & & $\begin{array}{l}\text { Full-term } \\
\text { infected } \\
\text { neonates }\end{array}$ & $\begin{array}{l}\text { Pre-term } \\
\text { neonates }\end{array}$ & $\begin{array}{l}\text { Pre-term } \\
\text { infected } \\
\text { neonates }\end{array}$ \\
\hline Gestational age (weeks) & $40.2 \pm 1.3$ & & $38.6 \pm 3.1$ & $31.9 \pm 0.9$ & $31 \pm 1.1$ \\
\hline Weight at birth (g) & $3435 \pm 73$ & & $2880 \pm 131$ & $1702 \pm 115.5$ & $1477 \pm 230.0$ \\
\hline Sex (female/male) & $7 / 3$ & & $3 / 8$ & $5 / 5$ & $5 / 4$ \\
\hline Peak value CRP (mg/dl) & & & $2.2 \pm 0.46$ & & $6.67 \pm 2.48$ \\
\hline CRP day 1 (mean \pm SEM) & & & $0.59 \pm 0.09$ & & $1.11 \pm 0.61$ \\
\hline Apgar score $1^{\prime}$ & $9.6 \pm 0.2$ & & $7.2 \pm 0.6$ & $6.5 \pm 0.55$ & $5.1 \pm 0.5$ \\
\hline \multirow[t]{2}{*}{$\begin{array}{l}\text { slCAM-1 (ng/ml) } \\
\text { [median (range)] }\end{array}$} & $\begin{array}{c}358.4 \pm 28.9 \\
{[353.4} \\
(233-538)]\end{array}$ & & $\begin{array}{c}710.7 \pm 56.6 \\
{[653.2} \\
(450-999)]\end{array}$ & $\begin{array}{c}467.7 \pm 44.5 \\
{[469.6} \\
(257-755)]\end{array}$ & $\begin{array}{c}1237.7 \pm 73.8 \\
{[1225.2} \\
(955-1769)]\end{array}$ \\
\hline & & $\begin{array}{l}p<0.0001^{*} \\
p=0.054^{* *}\end{array}$ & & & \\
\hline
\end{tabular}

\footnotetext{
* Refers to the difference between the levels of sICAM-1 in the non-infected and infected groups of neonates.

** Refers to the difference between the levels of sICAM-1 in non-infected full-term and premature neonates.

₹ Refers to the difference between the levels of sICAM-1 in infected full-term and premature neonates.
} 
$\pm 28.8 \mathrm{ng} / \mathrm{ml}, p<0.0001)$. The group of premature infants with infection also had higher levels of sICAM1 compared with those without infection $(1237.7 \pm$ 73.8 and $467.7 \pm 44.9 \mathrm{ng} / \mathrm{ml}$, respectively; $p<0.0001)$ and with healthy full terms $(p<0.0001$; Fig. 1). Prematurity combined with infection resulted in excessive increase of the levels of sICAM-1 in comparison with full-term infected newborns $(p<0.0001)$. In the absence of infection, the difference found between the groups of premature and full-term neonates was borderline statistically significant $(p=$ 0.054) (Table 1).

Neonates with infection and positive blood culture $(n=8)$ had very increased levels of sICAM-1 $(1185 \pm 120.3 \mathrm{ng} / \mathrm{ml})$ compared with those that had only clinical signs of infection $(n=13)(824.16 \pm$ $73.4 \mathrm{ng} / \mathrm{ml}, p=0.01)$, and all but one (20/21) had normal CRP values.

CRP values were normal in all samples except one on day 1 (when determination of sICAM-1 levels was performed as well) in full-term infected neonates $(0.59 \pm 0.09 \mathrm{mg} / \mathrm{dl})$. They increased on day $2(2.2 \pm$ $0.46 \mathrm{mg} / \mathrm{dl}$ ) and decreased, but without reaching normal levels, on day $4(1.19 \pm 0.32 \mathrm{mg} / \mathrm{dl}$; Fig. 2$)$. CRP values of premature neonates with infection on day 1 were found normal in all but one, but they increased the following days (day $2,4.64 \pm 1.93 \mathrm{mg}$ / dl; day $4,6.67 \pm 2.48 \mathrm{mg} / \mathrm{dl}$; Fig. 2).

In the subgroup of premature newborns without signs of infection, the gestational age $(r=-0.62, p$ $=0.05)$ and birth weight $(r=-0.65, p=0.04)$ negatively correlated with the levels of sICAM-1. Birth weight, but not gestational age, was higher in the neonates without infection either in the group of full-term or that of premature infants (full-term, $2880 \pm 131$ and $3435 \pm 73 \mathrm{~g}$; premature, $1477 \pm$ 230.0 and $1702 \pm 115.5 \mathrm{~g}$; with and without infection, respectively).

\section{Discussion}

The difficulties in diagnosing infection in the newborn are reflected in the great diversity of methods described in the literature ${ }^{11}$ and in the continuous efforts to establish either a single or a combination

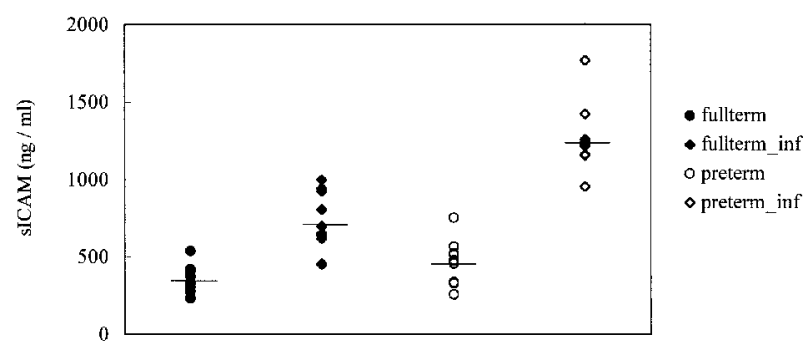

FIG. 1. sICAM-1 values of all groups. Horizontal lines represent the mean values of sICAM-1 of each group, open symbols refer to premature infants, and filled symbols refer to full-term infants.

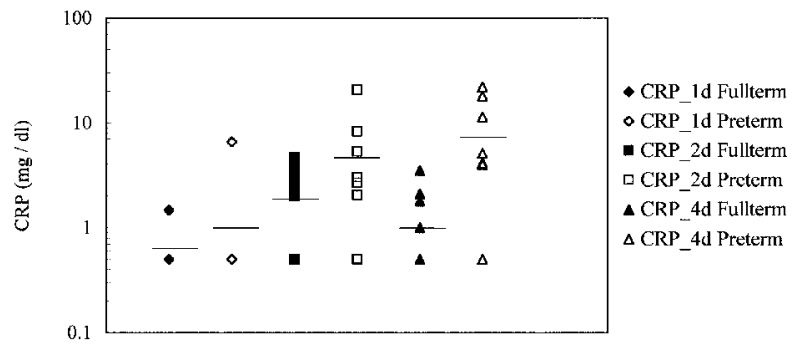

FIG. 2. Serial measurements of the CRP values at the first 4 days of full-term and pre-term neonates with infection. Horizontal lines represent the CRP mean values of each group on each day $(1 \mathrm{~d}$, first day; $2 \mathrm{~d}$, second day; $4 \mathrm{~d}$, fourth day), filled symbols refer to the group of full-term infants, and open symbols refer to the group of premature infants.

of markers that would provide useful information in the clinical decisions about antibiotic treatment that is nowadays given to all suspected severely sick babies. ${ }^{12}$

The results show distinctly different patterns of expression of sICAM-1 between premature and fullterm neonates as a function of septic process. Concentrations of sICAM-1 are very high in neonates with sepsis regardless of their gestational age. Even though only 10 out of 21 neonates with infection had positive blood culture, it is well known that a negative blood culture does not exclude sepsis. On the contrary, while the CRP levels, which are the most reliable marker in use, were normal at the day of sampling, the sICAM values were elevated in all infected neonates of the study, possibly indicative of a higher sensitivity to infection of this marker. The high number of negative blood cultures in cases of clinically diagnosed sepsis in combination with delayed elevation of CRP levels in neonates with infection further emphasizes the necessity for a more reliable index for early diagnosis. sICAM measurement is not simpler than CRP detection, but does, however, require a minimum amount of serum, equipment available to most hospital laboratories, gives results within the day, and could probably be incorporated in routine infection laboratory tests.

sICAM-1 was detected in all neonates, the gestational age of whom ranged from 25 to 41 weeks. This confirms the suggestion of Austgulen et $a l^{7}$ that constitutive shedding of at least this adhesion molecule is an established component of the immune system as early as the 24 th week of gestation.

Prematurity itself results in increased serum concentration of SICAM, as shown by the inverse strong correlation between the latter and the gestational age, although the mean value of sICAM in premature infants is borderline statistically significant compared with the corresponding level in full terms. An additional factor contributing to the elevation of sICAM could be birth weight, as indicated by the strong inverse correlation between the two parameters. 
Furthermore the combination of prematurity with infection seems to result in increased levels of the adhesion molecule sICAM-1. This is in accordance with Kuster and Degitz, ${ }^{8}$ who showed that sICAM-1 levels increased in a group of premature neonates with infection (24-36 weeks), and with Giannaki et al. ${ }^{13}$ who showed that in infection-free full-term neonates there is an increased release of both sICAM1 and soluble vascular cell adhesion molecule-1, although no infected neonates were included in this latter study. On the contrary, Austgulen et $\mathrm{al}^{7} \mathrm{did}_{\text {not }}$ find any differences in ICAM-1, vascular cell adhesion molecule-1 as well as E-selectin concentrations between the premature group of infected and noninfected neonates. The discrepancy among these studies may be due to differences in the classification of the newborn infected infants and the postnatal age of neonates at sampling. ${ }^{8,14}$

In conclusion, increased sICAM-1 levels can be detected in both full-term and premature neonates with sepsis as a response of the immune system to inflammatory stimuli. As neonates with infection had increased sICAM-1 levels and CRP levels within normal range at the time of the sampling, measurement of serum ICAM-1 could be a useful and early marker in neonatal sepsis. Assessment of sICAM-1 concentrations may be used as a diagnostic tool in neonates suspected of infection, resulting in earlier initiation of antibiotic therapy and therefore improving their outcome.

ACKNOWLEDGEMENTS. Melita Apostolou and Helen Dimitriou equally contributed to this study

\section{References}

1. Krediet T, Gerards L, Fleer A, van Stekelenburg G. The predictive value of CRP and I/T-ratio in neonatal infection. J Perinat Med 1992; 20: 479-485.

2. Pourcyrous M, Bada HS, Korones SB, Baselski V, Wong SP. Significance of serial C-reactive protein responses in neonatal infection and other disorders. Pediatrics 1993; 92: 431-435.

3. Berger C, Uehlinger J, Ghelfi D, Blau N, Fanconi S. Comparison of C-reactive protein and white blood cell count with differential in neonates at risk for septicaemia. Eur J Pediatr 1995; 154: 138-144.

4. Springer TA. Adhesion receptors of the immune system. Nature 1990; 346: 425-434.

5. Seth R, Raymond FD, Makgoba MW. Circulating ICAM-1 isoforms: diagnostic prospects for inflammatory and immune disorders. Lancet 1991; 338: 83-84.

6. Aoki S, Imai K, Yachi A. Soluble intercellular adhesion molecule-1 (ICAM1) antigen in patients with rheumatoid arthritis. Scand J Immunol 1993: 38: $485-490$.

7. Austgulen R, Arntzen KJ, Haereid PE, Aag S, Dollner H. Infections in neonates delivered at term are associated with increase serum levels of ICAM-1 and E-selectin. Acta Paediatr 1997; 86: 274-280.

8. Kuster H, Degitz K. Circulating ICAM-1 in neonatal sepsis. Lancet 1993; 341: 506.

9. Edgar JD, Wilson DC, McMillan SA, et al. Predictive value of soluble immunological mediators in neonatal infection. Clin Sci 1994; 87: $165-171$.

10. Smulian JC, Bhandari V, Cambell WA, Rodis JF, Vintzileos AM. Value of umbilical artery and vein levels of interleukin- 6 and soluble intracellular adhesion molecule- 1 as predictors of neonatal hematologic indices and suspected early sepsis. J Matern Fetal Med 1997; 6: 254-259.

11. Fowlie PW, Schmidt B. Diagnostic tests for bacterial infection from birth to 90 days - a systemic review. Arch Dis Child Fetal Neonatal Ed 1998; 78: F92-F98.

12. Hansen A, Verder H, Staun-Olsen P. Soluble intercellular adhesion molecule and C-reactive protein as early markers of infection in newborns. J Perinat Med 2000; 28: 97-103.

13. Giannaki G, Xyni K, Rizos D, Phokas I. Comparative study of serum soluble VCAM-1 and ICAM-1 levels in the early neonatal period. Acta Paediatr 1999: 88: 1413-1414.

14. Little S, Dean T, Bevin S, et al. Role of elevated plasma soluble ICAM-1 and bronchial lavage fluid IL-8 levels as markers of chronic lung disease in premature infants. Thorax 1995; 50: 1073-1079.

Received 20 December 2001 Accepted 31 January 2002 


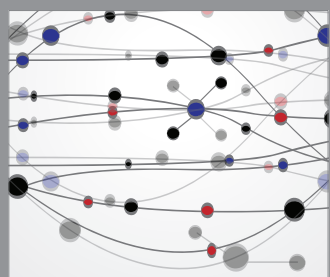

The Scientific World Journal
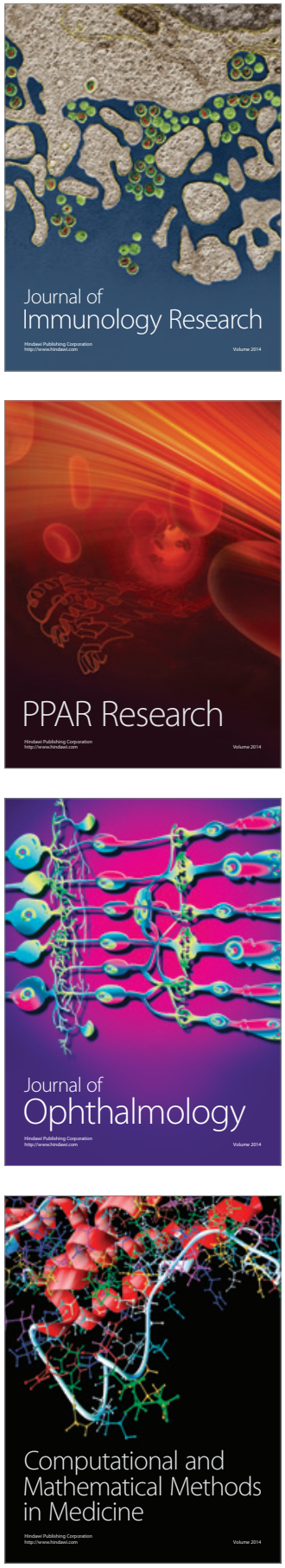

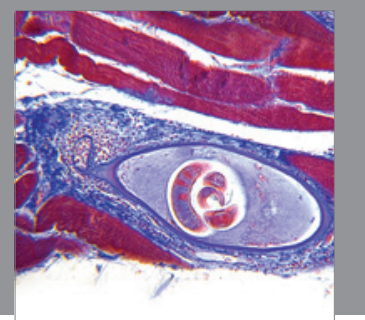

Gastroenterology

Research and Practice
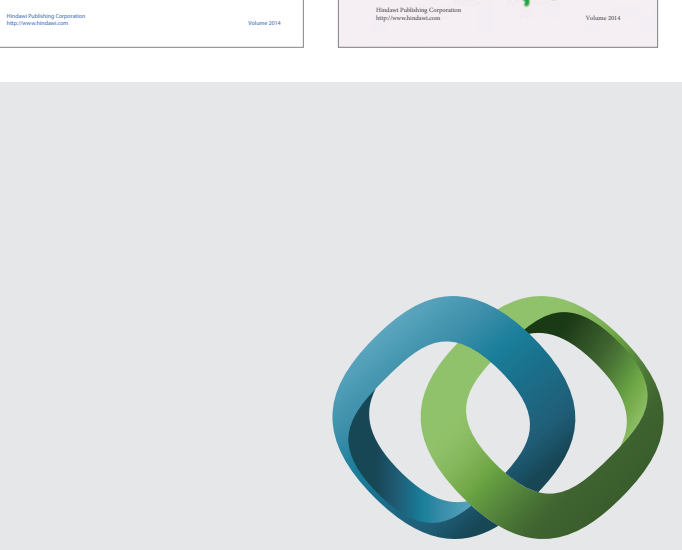

\section{Hindawi}

Submit your manuscripts at

http://www.hindawi.com
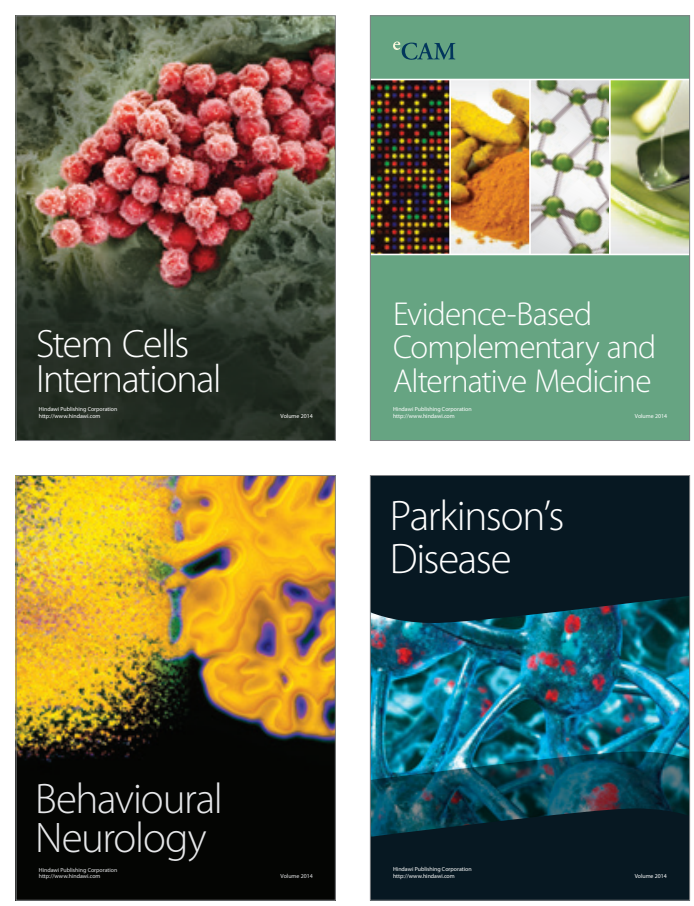

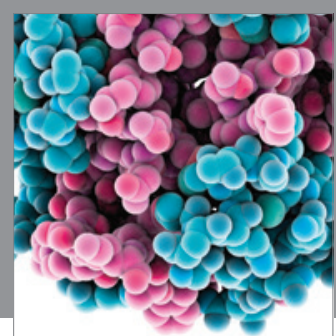

Journal of
Diabetes Research

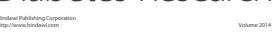

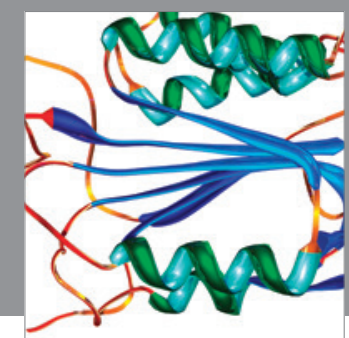

Disease Markers
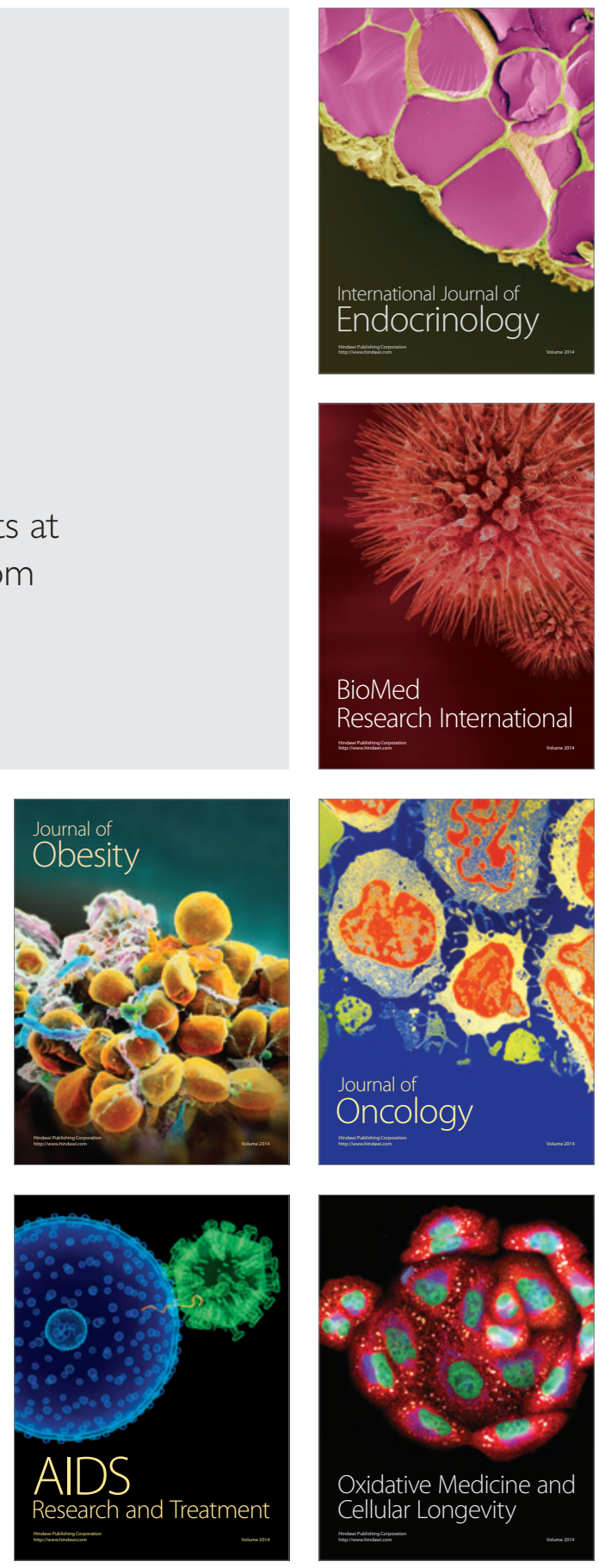